\title{
Salvaging the C-CAPM: Currency Carry Trade Risk Premia and Conditioning Information
}

\author{
Abhay Abhyankar, Angelica Gonzalezł Olga Klinkowska
}

September 2011

\begin{abstract}
We use a standard consumption-based asset pricing model incorporating conditioning information to explain the risk-return profile of currency carry trade portfolios. In contrast to previous work, we use a scaled stochastic discount factor instead of scaled or managed portfolio returns. Our conditioning variable is a forward-looking measure of the net foreign assets, arising from an intertemporal budget constraint, that allows for valuation changes in foreign assets and liabilities and has strong predictive power for multilateral exchange rates. We find that our conditional consumption CAPM that allow for time variation in consumption betas can price a large part of the variation in cross-section of carry trade portfolios. Taken together our results suggest that the consumption-based models do still have a role to play in explaining excess returns on carry trade strategies.

JEL classification: G0, G10, G12

Keywords: Consumption CAPM, Fama-MacBeth Regressions, Net Foreign Assets, Conditioning Information, Conditional Asset Pricing Models
\end{abstract}

\footnotetext{
${ }^{*}$ University of Edinburgh Business School, 29 Buccleuch Place, Edinburgh, EH8 9JS, email: A.Abhyankar@ed.ac.uk.

${ }^{\dagger}$ University of Edinburgh Business School, 29 Buccleuch Place, Edinburgh, EH8 9JS, email: Angelica.Gonzalez@ed.ac.uk.

${ }^{\ddagger}$ University of Aberdeen Business School, Edward Wright Building, Dunbar Street, Aberdeen, AB24 3QY, UK, email: o.klinkowska@abdn.ac.uk.
} 


\section{Introduction}

Currency carry trades - borrowing in a low-interest rate funding currency with a higher yielding deposit in a target currency - have been shown to be consistently profitable over the last few decades. There is an ongoing debate as to whether the risk-return profile observed for carry trade portfolios can be better explained by traditional risk factors like consumption growth or by non-risk based factors. We add to this literature by providing new evidence that a conditional Consumption-CAPM (C-CAPM) with a state dependent stochastic discount factor and an economically motivated conditioning variable - fluctuations in net foreign assets - is able to account well for the cross-section of carry trade risk premia.

Currency carry trades are widely used by foreign exchange traders. Lustig and Verdelhan (2008) observe that a carry trade strategy levered up to match the volatility of stock returns would, over a period of 25 years, produce a return of $\$ 3.36$ for every dollar invested compared to $\$ 2.71$ for an investment in the stock market yielding a cumulative return difference of $65 \%$ ! However, a central tenet of international finance, uncovered interest rate parity (UIP), implies that investors should expect exchange rates to move in a way that equalizes the rates of return on equally risky assets denominated in different currencies. If this theory holds then carry trades would yield no excess profits. A large literature, reviewed in Engel (1996), uses data on individual currency pairs and finds that the UIP condition is violated except in the case of very high inflation currencies.

In a recent work, Lustig and Verdelhan (2007) shift the focus from individual currencies to investable multi-currency portfolios that deliver trading strategies with higher excess returns and Sharpe ratios than seen for individual currency pairs. They find that a standard consumption-based asset pricing model explains the cross-section of risk across carry trade portfolios sorted on the basis of inter-country interest rate differentials. However Burnside (2011), using similar data, finds that this standard risk-based explanation is not reflected in the data. Following this debate there have been several papers that have found evidence in support of both risk-based and non-risk based ${ }^{1}$ factors that explain the observed carry trade risk premium. We contribute to this literature by showing that the time varying risk premium in carry trade strategies can be substantially captured by a conditional consumption-based asset pricing model (C-CAPM) with a state-dependent or scaled stochastic discount factor. We are not the first to use models incorporating conditioning information. Indeed, Lustig and Verdelhan (2007) use a conditional version of the C-CAPM with the inter-country interest rate differential as an instrumental variable based on empirical evidence of its predictive ability for exchange rates. However, their conditional C-CAPM incorporates conditioning information through managed portfolios. In contrast our paper is the first, as far as we are aware, to use a linearized C-CAPM stochastic discount factor that is "scaled" using a conditioning variable that allows it to be "state dependent". The conditioning variable we use is a measure of Net Foreign Assets (NFA) first used by Gourinchas and Rey (2007). NFA is based on the accounting identity linking US foreign assets, liabilities, exports and imports. This identity implies that when the US accumulates foreign liabilities in excess of its assets, there must be an expectation that the international debt will ultimately be repaid using the proceeds from future net exports and/or returns on foreign assets, or that the US will eventually default. Like CAY, used in Lettau and Ludvigson (2001a, 2001b), NFA is a forward looking

\footnotetext{
${ }^{1}$ Burnside, Eichenbaum and Rebelo (2011) provide a comprehensive review of recent research on both risk and non-risk based explanations.
} 
measure that has predictive power for exchange rates and effectively summarizes underlying fundamentals that influence exchange rate movements.

Our main results can be summarized as follows. We find that a conditional version of a standard C-CAPM does a good job of pricing the cross-section of carry trade portfolios. Our conditioning variable, U.S. net foreign assets, relate changes in foreign assets and liabilities to multilateral exchange rates. Our model, in contrast to prior work on exchange rates, uses conditioning information to scale the stochastic discount factor rather than scaling test asset returns. We find, using standard Fama-MacBeth regressions, that this scaled C-CAPM has high explanatory power for the risk return profile of carry trade portfolios. This evidence is further supported by tests that incorporate theoretical restriction on the time series intercepts of the model. We also find that our results are robust to using a longer span of annual and quarterly data on carry trade excess returns.

The rest of the paper is organized as follows. In Section 2 we briefly outline related prior research on the carry trade risk premium and efforts to explain it focussing on risk-based models. We also provide details of previous work in this area that uses conditional asset pricing models. Next, in Section 3 we discuss the empirical methodology we use with a focus on tests of conditional asset pricing models. Section 4 describes the data we use and Section 5 provides a description of our results and test for robustness. Section 6 concludes the paper.

\section{Background and Related Research}

We now briefly outline related work on risk and non-risk based explanations of the risk-return profile of carry trade portfolios. This literature is growing rapidly and therefore we focus here on key papers that relate to our work. We refer the reader to recent survey papers (for example Burnside, Eichenbaum and Rebelo, 2011) for details. Next, based on Ludvigson (2011), we distinguish between the two ways in which conditioning information has been incorporated in to tests of asset pricing models; either by scaling returns i.e. using managed portfolios as in Lustig and Verdelhan (2007) and Lustig, Roussanov and Verdelhan (2011). Alternately as in this paper, we scale the elements of the stochastic discount factor (as in Lettau and Ludvigson, 2001b) using lagged fluctuations in the net foreign assets. Our conditioning variable reflects underlying fundamentals that affect exchange rates and also has good predictive ability for multilateral exchange rates (Gourinchas and Rey,2007).

\subsection{Models with Conventional Risk Factors}

Lustig and Verdelhan (2007) are the first to use currency portfolios rather than individual currency pairs. They form eight portfolios, re-balanced every period, sorted on the basis of the interest rate differential between country pairs from the lowest interest rate to the highest interest rate currencies. They use the Yogo (2006) version of the C-CAPM that also nests the canonical C-CAPM with non-durable consumption growth. In the Yogo (2006) model the linearized stochastic discount factor can, in its unconditional version, be written as:

$$
E\left(R_{i, t}^{e}\right)=b_{1} \operatorname{Cov}\left(\Delta c_{t}, R_{i, t}^{e}\right)+b_{2} \operatorname{Cov}\left(\Delta d_{t}, R_{i, t}^{e}\right)+b_{3} \operatorname{Cov}\left(r_{t}^{w}, R_{i, t}^{e}\right)
$$

where $R_{i, t}^{e}$ is the excess return on the $i$ th carry trade portfolios, $\Delta c_{t}$ is the non-durable consumption growth rate, $\Delta d_{t}$ is the durable consumption growth rate and $r_{t}^{w}$ is the return on 
the stock market index. Estimated values of the coefficients $b$ can be used to back out estimates of the relative risk aversion parameter etc. for a given model and set of data. Lustig and Verdelhan (2007) find using standard Fama-MacBeth regressions, that excess annual returns across 8 carry trade portfolios over the period 1953-2002 can be explained by consumption betas. For example, they find that their benchmark model, the Yogo C-CAPM (with three factors; $\Delta c_{t}, \Delta d_{t}$ and $r_{t}^{w}$ ), explains $87 \%$ of the variation in annual returns across their 8 currency portfolios compared to $74 \%$ using a C-CAPM with two factors $\left(\Delta c_{t}, \Delta d_{t}\right)$. In contrast a C-CAPM based on an Epstein-Zin utility function (with two factors; $\Delta c_{t}$ and $r_{t}^{w}$ ) and the standard C-CAPM (with one factor $\Delta c_{t}$ ) have cross-sectional R-squared's of about $20 \%$ and $18 \%$ respectively. However they also find that these models, despite their good cross-sectional fit to the data, deliver very high values of the relative risk aversion parameter. This is similar to the evidence for the equity market reported by Yogo (2006).

Burnside (2007), using similar data, puts forward two main points in regard to the results in Lustig and Verdelhan (2007). The first is that he finds little statistical evidence that aggregate consumption growth risk is priced in currency markets and second that the Lustig and Verdelhan (2007) measure of fit overstates their results. In their reply, Lustig and Verdelhan (2007) raise a number of points that support their conclusions that have again been discussed in Burnside (2011).

Another example of a risk-based model is Verdelhan (2010). He develops a consumptionbased model with habit formation, inspired by Abel (1990) and Campbell and Cochrane (1999), to explain the risk-return profile seen in carry trades. In his model, a domestic investor expects to receive a positive foreign currency excess return in bad times when he is more risk averse than his foreign counterpart. In other words, time periods of high risk aversion correspond to low interest rates in the home country. Thus, domestic investors expect positive currency excess returns when domestic interest rates are low and foreign interest rates are high. Verdelhan (2010) uses currency excess returns for 8 developed countries as well as the 6 size and 25 Fama-French book-to-market and size portfolios. He finds that the hypothesis that pricing errors are zero cannot be rejected at conventional confidence levels. We note that the stochastic discount factor in the Verdelhan model, like in Campbell and Cochrane (1999), has a pricing kernel that is an approximate state-dependent linear function of consumption growth. Next we outline recent work where multifactor asset pricing models with empirically motivated factors, in the spirit of Fama and French $(1992,1993)$ are developed, and used to explain the cross-section of carry trade portfolio returns.

\subsection{Empirical Factor-Based Models}

Lustig, Roussanov and Verdelhan (2011) construct empirical risk factors, in the spirit of Fama and French $(1992,1993)$, designed to price the average payoffs to portfolios of carry trade strategies. Using monthly data, over the period 1983-2009, they use data on spot and forward contracts to create six currency portfolios from currency pairs sorted on the basis of the forward discount. Their first portfolio contains the lowest interest rate currencies while the last contains the highest interest rate currencies. Using principal components on this set of portfolio returns), they find that the first two principal components of account explain most of the time series variation in currency returns and also have meaningful economic interpretations. The first principal component or "level" factor is correlated to the average excess return on all foreign currency portfolios which they term as $D O L$ or the dollar risk 
factor. The second principal component is like a "slope" factor and is essentially the difference between the return on the sixth and the first portfolios - they call this factor $H M L_{F X}$. The stochastic discount factor in their model is:

$$
m_{t+1}=1-b_{D O L}\left(D O L_{t+1}-\mu_{D O L}\right)-b_{H M L_{F X}}\left(H M L_{F X, t+1}-\mu_{H M L_{F X}}\right)
$$

where $\mu_{D O L}$ and $\mu_{H M L_{F X}}$ are the factor means and $b_{D O L}, b_{H M L_{F X}}$ the factor coefficients. They use these empirical factors to test the cross-section of currency returns and find that the risk price of the $H M L_{F X}$ or carry factor (the second principal component) is $4.16 \%$ per annum while the risk price of the dollar factor (the first principal component) is $3.46 \%$ per annum. Further, using cross-sectional regressions they find that the pricing errors are small (RMSE is 96 basis points) and the adjusted R-squared is 70 percent. They also find that the null that the pricing errors are zero cannot be rejected, regardless of the estimation procedure with p-values all exceeding $5 \%$.

In closely related work Menkhoff, Sarno, Schmeling and Schrimpf (2010) find that a measure of global volatility ${ }^{2}$ obtained from currency markets also explains the cross-section of our currency portfolios. Their stochastic discount factor which can be written as:

$$
m_{t+1}=1-b_{D O L}\left(D O L_{t+1}-\mu_{D O L}\right)-b_{V O L} \Delta \sigma_{t+1}^{F X}
$$

where $D O L_{t+1}$ is and $\Delta \sigma_{t+1}^{F X}$ is their proxy for innovation to global FX volatility. They find, using 5 carry trade portfolios, that their volatility factor has a negative market price of risk. Further they find the cross-sectional model has good fit with the data (R-squared of 90\%) and they also cannot reject the null that the HJ-distance is zero.

\subsection{Non-Risk Based Models}

We now describe in brief recent work that relies on non-risk based models (see Burnside, Eichenbaum and Rebelo (2011) for a comprehensive review) that use the idea of disaster risk or market microstructure related factors like price pressure to explain the observed excess returns on carry trade portfolios. For example, Burnside, Eichenbaum, Kleschelski and Rebelo (2011) argue that the payoffs to the carry trade can, at least in part, be explained by the presence of rare disasters or peso problems. They study a hedged carry trade strategy that is immune to large losses such as those potentially associated with a peso event. Using data on currency options to estimate the average risk-adjusted payoff to this trade they find that this payoff is smaller than the corresponding payoff to the unhedged carry trade. They conclude that a peso event reflects high values of the SDF in the peso state rather than very large negative payoffs to the unhedged carry trade in that state. In other words, they find that the main characteristic of a peso event is that the SDF increases sharply, suggesting that investors fear disastrous outcomes.

Burnside, Eichenbaum and Rebelo (2011) explore an alternative explanation that relies on the existence of price pressure in foreign exchange markets for the profitability of the carry trade strategies. Here price pressure is the price at which investors can buy or sell currencies depends on the quantity they wish to transact and this introduces a wedge between marginal and average payoffs to a trading strategy. As a result, observed average payoffs can be positive

\footnotetext{
${ }^{2}$ This is related closely to work on equity markets in Ang, Hodrick, Xing and Zhang (2006) and Adrian and Rosenberg (2008).
} 
even though the marginal trade is not profitable. So, traders do not increase their exposure to the strategy to the point where observed average risk-adjusted payoffs are zero. We now turn to a brief description of how conditioning information is incorporated into empirical tests of asset pricing models and relate these to our paper.

\subsection{Linear Factor Models with Time-Varying Coefficients}

Cochrane (1996) advocates using instruments to incorporate conditioning information in tests of conditional asset pricing models. Ferson and Harvey (1999), for example, use lagged economy-wide indicators as scaling variables in cross-sectional asset pricing tests. Jagannathan and Wang (1996) find that the performance of the classical CAPM is dramatically improved by conditioning the market factor on macroeconomic indicators such as the term premium. The conditioning variables employed in these papers are variables that have predictive power for excess equity returns like the dividend yield and interest rate differentials and thus reflect underlying fundamentals in the economy. We note that tests of conditional models are subject to the Hansen and Richard (1987) critique that conditioning instruments may not fully reflect an investors' set of conditioning information. We now draw on Ludvigson (2011) and provide a brief background to the conditional C-CAPM we use and link it to prior work on the carry trade risk-return trade-off.

We know (see for example, Cochrane, 1996) that consumption-based asset pricing models imply that while expected returns can vary across time and assets, expected discounted returns should always be the same for every asset. In other words the following conditional relationship holds:

$$
E_{t}\left[M_{t+1} R_{i, t+1} \mid x_{t}\right]=1
$$

where $R_{t}$ is the gross return on asset $i$ and $M_{t+1}$ the stochastic discount factor which equals the marginal rate of substitution in consumption. In empirical work the unconditional implications of the above Euler equation are used by applying the law of iterated expectations and conditioning down to get:

$$
\begin{aligned}
E\left[E_{t}\left(M_{t+1} R_{i, t+1} \mid x_{t}\right)\right] & =1 \\
E\left[M_{t+1} R_{i, t+1}\right] & =1
\end{aligned}
$$

As detailed in Cochrane (2005) we can do more than just condition down by using instruments and expanding the asset space by creating "managed portfolios" and incorporating conditioning information using what Cochrane (1996) refers to as "scaled returns":

$$
E\left[M_{t+1}\left(R_{i, t+1} \otimes\left(\begin{array}{ll}
1 & x_{t}
\end{array}\right)^{\prime}\right)\right]=1
$$

To focus this discussion, we use the example of the canonical power utility C-CAPM. In this case we can linearize the $\operatorname{SDF} M_{t+1}=\beta\left(\frac{C_{t+1}}{C_{t}}\right)^{-\gamma}$ and write it as $M_{t+1} \simeq \beta-\beta \gamma \Delta c_{t+1}$ where $\Delta c_{t+1}=\ln \left(\frac{C_{t+1}}{C_{t}}\right)$ and $\beta$ is the $\gamma$ is the coefficient of relative risk aversion. Using excess returns we have the following specification:

$$
E\left[\left(\beta-\beta \gamma \Delta c_{t+1}\right)\left(R_{i, t+1}^{e} x_{t}\right)\right]=0
$$


Lustig and Verdelhan (2007) estimate the above conditional C-CAPM where $R_{i, t+1}^{e}$ is the returns on the $i$ th excess currency carry trade portfolio and their conditioning variable $x_{t}$ is $\Delta \bar{R}_{t}$ is the average interest rate difference on their portfolios 1 and 7 , i.e. the portfolios with the highest and the smallest interest rate differentials. Thus they estimate the following model:

$$
E\left[\left(\beta-\beta \gamma \Delta c_{t+1}\right)(\underbrace{R_{i, t+1}^{e} \Delta \bar{R}_{t}})\right]=0
$$

where $\left(R_{i, t+1}^{e} \Delta \bar{R}_{t}\right)$ are the managed portfolios that lever up when the interest rate with the U.S. is large.

Lustig, Roussanov and Verdelhan (2011) also use managed portfolios and allow for timevarying factor betas in their empirically motivated APT type model that has factors $D O L$ and $H M L_{F X}$ as defined earlier. To create managed portfolios they multiply each currency excess return with the corresponding beginning-of-month forward discount normalizing this quantity by subtracting the average forward discount across currencies and dividing by the cross-sectional standard deviation of forward discounts in the given period. They find, using this 'augmented' set of managed portfolios, that the market prices of risk in their model are positive and significant and similar to those using unconditional returns. Next, they estimate factor loadings using rolling windows instead of incorporating conditioning information explicitly. Specifically, they first run time series regressions using rolling windows of 36 months to estimate the factor betas. They then use these average factor betas in a set of cross-sectional regressions to estimate the factor risk prices or $\lambda^{\prime} s$. It is not feasible however to apply this methodology in the case of consumption-based models since we have adequate data at quarterly frequency. The only other paper, that we know of, that uses conditioning information in the case of currency carry trade portfolios is Nitschka (2007), who also scales returns and uses managed portfolios rather than scaling the stochastic discount factor.

In contrast to the above papers from the carry trade literature we allow for conditioning information by "scaling factors" (see Cochrane, 1996), in the pricing kernel. In this case we write the stochastic discount factor as $M_{t+1}=b_{t} f_{t+1}$ where $b_{t}=b_{0}+b_{1} z_{t}$ in the following manner:

$$
M_{t+1}=b_{t}^{\prime} f_{t+1}=b_{t}^{\prime}\left(f_{t+1} \otimes\left(\begin{array}{ll}
1 & x_{t}
\end{array}\right)^{\prime}\right)
$$

As Ludvigson (2011) points out "scaling returns is appropriate if conditioning information is used to model time-varying covariances between $M_{t+1}$ and returns... while scaling factors is appropriate if the conditioning information is implied by preferences $M_{t+1}$ even if the covariances studied are constant over time because they are based on unconditional expectations $E\left[M_{t+1} R_{i, t+1}\right]=1$ ". Lettau and Ludvigson (2001b), for example, use an "economically" motivated conditioning variable $C A Y$ that exploits the relation between consumption and wealth through the stand in investors' budget constraint. $C A Y$ also has, as theoretically expected, predictive power for equity excess returns and this further justifies its use as a conditioning variable. 


\subsection{Conditioning Variable}

In this paper, we use as a conditioning variable, a measure of net foreign assets, first employed by Gourinchas and Rey (2007) to study how capital gains on gross external assets provide an alternative channel, to the familiar channel via trade flows, for international balance of payments adjustment. They show that an alternative way of satisfying the country budget constraint would be for the valuation of foreign holdings of home assets to drop (increase); e.g. through exchange rate depreciation (appreciation)results . Building on Lettau and Ludvigson (2001a), their starting point is the accumulation identity for net foreign assets between periods $t$ and $t+1$ :

$$
N A_{t+1} \equiv R_{t+1}\left(N A_{t}+N X_{t}\right)
$$

where $\mathrm{NX}_{t}$ is net exports (i.e., the difference between exports $X_{t}$ and imports $M_{t}$ of goods and services), $\mathrm{NA}_{t}$ is net foreign assets (i.e. the difference between gross external assets $\mathrm{A}_{t}$ and gross external liabilities $\mathrm{L}_{t}$ measured in domestic currency) and $\mathrm{R}_{t+1}$ denotes the (gross) return on assets $\mathrm{R}_{t+1}^{a}$ and the gross returns on liabilities $\mathrm{R}_{t+1}^{l}$. Dividing by $\mathrm{W}_{t}$ and defining $\widehat{Z}_{t}=Z_{t} / W_{t}$, where $\mathrm{Z}_{t} \in\left\{X_{t}, M_{t}, A_{t}, L_{t}\right\}$, leads to:

$$
\widehat{A}_{t+1}-\widehat{L}_{t+1}=\frac{R_{t+1}}{\Gamma_{t+1}}\left(\widehat{A}_{t}-\widehat{L}_{t}+\widehat{X}_{t}-\widehat{M}_{t}\right)
$$

where $\Gamma_{t+1}=W_{t+1} / W_{t}$ is the growth rate of wealth between $\mathrm{t}$ and $\mathrm{t}+1$. The accumulation identity in eq.(11) can be written for a deterministic economy using equilibrium values for the wealth ratio, i.e., $\widetilde{Z_{t}}=Z_{t} / W_{t}$, as:

$$
\widetilde{A}_{t+1}-\widetilde{L}_{t+1}=\frac{\widetilde{R}_{t+1}}{\widetilde{\Gamma}_{t+1}}\left(\widetilde{A}_{t}-\widetilde{L}_{t}+\widetilde{X}_{t}-\widetilde{M}_{t}\right)
$$

where $\widetilde{R}_{t+1}$ and $\widetilde{L}_{t+1}$ denote the equilibrium return on the net foreign assets portfolio and the growth rate of wealth in the deterministic economy. The difference between eq.(12) and eq.(13) is the budget constraint "in deviation from trends". Using the notation in Gourinchas and Rey (2007) we define $\varepsilon_{t}^{z} \equiv \ln \left(\widehat{Z}_{t} / \widetilde{Z}_{t}\right), \widehat{r}_{t+1}=\ln \left(R_{t+1} / \widetilde{R}_{t+1}\right)$ and $\varepsilon_{t+1}^{\Delta w}=\ln \left(\Gamma_{t+1} / \widehat{\Gamma}_{t+1}\right)$. By assuming that $\varepsilon_{t}^{z}, \widehat{r}_{t+1}$ and $\varepsilon_{t+1}^{\Delta w}$ are stationary and small we can write $\ln \widehat{Z}_{t}=\ln \left(\widetilde{Z}_{t}\right)+\varepsilon_{t}^{z}$; e.g. $\ln \widehat{Z}_{t}$ is written in terms of a deterministic component and a stationary one. Under the assumption that the trend components $\widetilde{Z}_{t}$ have a common trend, a log-linear approximation of the external constraint around its trend satisfies:

$$
n x a_{t+1} \approx \frac{1}{\rho} n x a_{t}+r_{t+1}+\Delta n x_{t+1},
$$

where:

$$
n x a_{t} \equiv\left|\mu^{a}\right| \varepsilon_{t}^{a}-\left|\mu^{l}\right| \varepsilon_{t}^{l}+\left|\mu^{x}\right| \varepsilon_{t}^{x}-\left|\mu^{m}\right| \varepsilon_{t}^{m},
$$

and it denotes cyclical external imbalances and $\Delta n x_{t+1} \equiv\left|\mu^{x}\right| \Delta \varepsilon_{t+1}^{x}-\left|\mu^{m}\right| \Delta \varepsilon_{t+1}^{m}-\varepsilon_{t+1}^{\Delta w}$ (de-trended net export growth), $\mu^{x}=\frac{1}{T} \sum \frac{\widetilde{X}_{t}}{\widetilde{X}_{t}-\widetilde{M}_{t}}$ (the average trend share of exports in the 
trade balance), $\mu^{m}=\mu^{x}-1 ; \mu^{a}=\frac{1}{T} \sum \frac{\widetilde{A}_{t}}{\widetilde{A}_{t}-\widetilde{L}_{t}}$ (the average trend share of assets in the net foreign assets), $\mu^{l}=\mu^{a}-1$ and $\rho \equiv 1+\frac{1}{T} \sum \frac{\widetilde{X}_{t}-\widetilde{M}_{t}}{\widetilde{A}_{t}-\widetilde{L}_{t}}$.

Gourinchas and Rey (2007) show that, under some regularity conditions (including $n x a_{t}$ satisfying a no-Ponzi condition), the intertemporal external constraint can be written as:

$$
n x a_{t} \approx-\sum_{j=1}^{+\infty} \rho^{j} E_{t}\left[r_{t+j}+\Delta n x_{t+j}\right] .
$$

This equation shows that movements in the de-trended trade balance and the net foreign asset position must forecast either future portfolio returns, or future net exports growth, or both. So there are two channels of adjustment to a net export imbalance; the usual trade channel, and an asset valuation channel. Note that the latter, represented in $\mathrm{r}_{t+j}$, can take place by changes in the nominal exchange rate, if the gross asset positions for assets and liabilities tend to be denominated in different currencies. In our application, we use $n x a$ in a manner analogous to cay in Lettau and Ludvigson (2001b). In our case $n x a$ reflects underlying fundamentals that determine the exchange rate for a country with regard to a set of other countries and has strong predictive power for exchange rates.

\section{Methodology}

The key papers that we build on Lustig and Verdelhan (2007) and Burnside (2011) use traditional asset pricing tests based on the Fama-MacBeth procedure or GMM-based cross-sectional regressions. However, the model we estimate is a conditional factor model and this results in two methodological points that need to be considered. The first is that the times series betas from our model are not the same as the conditional consumption beta of the classic C-CAPM. Second, we also need to take account of the issues raised in Lewellen and Nagel (2006) who argue that conditional CAPM betas which they estimate with rolling regressions are not volatile enough to explain the large excess returns on size and book-market sorted portfolios. Unfortunately, as indicated earlier, their empirical tests cannot be directly applied to the consumption CAPM, because of the absence of high frequency consumption data. Nevertheless, we take account of the Lewellen and Nagel (2006) critique and following Ludvigson (2011) report results of tests of theoretical restrictions on the time series intercepts that should be satisfied in scaled consumption-based asset pricing models.

\subsubsection{Cross-Sectional Regression Tests}

We estimate our model using the standard Fama-MacBeth procedure. In the first stage, we run the time-series regressions and estimate betas:

$$
R_{i, t}^{e}=\alpha_{i, t}+\beta_{i, t} f_{t}+e_{i t}
$$

where $R_{i, t}^{e}$ is the excess return on the carry trade portfolios and $f_{i, t}$ is the factor in our linearized stochastic discount factor. In the case of our conditional model we estimate the model where the stochastic discount factor is given by $M_{t}=a_{t}+b_{t} f_{t}$ where $a_{t}=a_{o}+a_{1} z_{t-1}$ and $b_{t}=b_{0}+b_{1} z_{t-1}$ resulting in a time series regression of the following type:

$$
R_{i, t}^{e}=a_{o}+a_{1} z_{t-1}+b_{0} f_{t}+b_{1}\left(f_{t} \cdot z_{t-1}\right)+\epsilon_{i t}
$$


i.e. we now have additional factors $z_{t-1}$ and $z_{t-1} f_{i, t}$. In the case of the standard C-CAPM we estimate using $n x a_{t-1}$ the following regression:

$$
R_{i, t}^{e}=a_{o}+a_{1 n x a, t-1}+b_{0} \Delta c_{t}+b_{1}\left(\Delta c_{t} \cdot n x a_{t-1}\right)+\epsilon_{i t}
$$

In the second stage, we run the cross-sectional regressions of excess returns on the estimated betas at each time period in the sample:

$$
\bar{R}_{i}^{e}=\hat{\beta}^{\prime} \lambda_{t}+\alpha_{i t}
$$

The second stage of the Fama-MacBeth procedure results in a time series of estimates of $\left\{\hat{\lambda}_{t}\right\}_{t=1}^{T}$, and a time series of pricing errors, $\left\{\hat{\alpha}_{i t}=\bar{R}_{i}^{e}-\hat{\beta}^{\prime} \hat{\lambda}_{t}\right\}_{t=1}^{T}$. The parameter estimates $\hat{\lambda}$ and pricing errors $\hat{\alpha}_{i}(i=1, \ldots, N)$ are then the averages of the appropriate time-series estimates: $\hat{\lambda}=E_{T}\left(\hat{\lambda}_{t}\right)$ and $\hat{\alpha}_{i}=E_{T}\left(\hat{\alpha}_{i t}\right)$. The coefficients of interest are $\lambda$ 's which represent the factor risk prices. The Fama-MacBeth procedure uses the standard deviations of the crosssectional regression estimates to generate the sampling errors for the parameter estimates: $\operatorname{cov}(\hat{\lambda})=\frac{1}{T} E_{T}\left[\left(\hat{\lambda}_{t}-\hat{\lambda}\right)\left(\hat{\lambda}_{t}-\hat{\lambda}\right)^{\prime}\right]$ and $\operatorname{cov}(\hat{\alpha})=\frac{1}{T} E_{T}\left[\left(\hat{\alpha}_{t}-\hat{\alpha}\right)\left(\hat{\alpha}_{t}-\hat{\alpha}\right)^{\prime}\right]$.

It is well-known, however, that two-step regressions suffer from an errors-in-variable problem since the betas used in the second pass are estimates of the true unknown betas. We therefore report standard errors using the Shanken (1992) correction which assumes that returns are stationary and conditionally homoskedastic. However we note, as shown in Jagannathan and Wang (1998), that conventional t statistics in the presence of conditional heteroskedasticity do not necessarily overstate the precision of the standard errors. Further, the Shanken correction is directly related to the magnitude of each coefficient and inversely related to the variability of the pricing factors. Lettau and Ludvigson (2001b) point out that macro factors are not very volatile and as a result this tends to "blow up" the Shanken correction factor so that the corresponding t statistics are not significant.

We also use an alternate way of dealing with the problem of generated regressors advocated by Cochrane (2005). In this approach, both time-series and cross-sectional moments are minimized simultaneously. The moments are the following:

$$
g_{T}(\theta)=\left[\begin{array}{c}
E\left(R_{i, t}^{e}-a-\beta_{i, t} f_{t}\right) \\
E\left[\left(R_{i, t}^{e}-a-\beta_{i, t} f_{t}\right) \otimes f_{t}\right] \\
E\left(\bar{R}_{i}^{e}-\beta_{i} \lambda_{i}\right)
\end{array}\right]=\left[\begin{array}{c}
0_{(N x 1)} \\
0_{(N L x 1)} \\
0_{(N x 1)}
\end{array}\right]
$$

where $a_{(N \times 1)}$ is a vector of constants for the time-series regressions; $\beta_{(N \times L)}$ is a matrix of $L$ factor loadings for the $N$ test assets; $\lambda_{(L \times 1)}$ is a vector of beta risk prices; $\otimes$ denotes the Kronecker product and 0 denotes conformable vectors of zeros. The parameter vector in this GMM system is $\theta^{\prime}=\left[\begin{array}{lll}a^{\prime} & \beta^{\prime} & \lambda\end{array}\right]^{\prime}: a$ and $\beta$ are identified by the first two sets of moment conditions and the cross-sectional estimates of $\lambda$ are identified by the third set of moments weighted by the time-series $\beta$.

The GMM estimation of this system in eq.(21) with the identity weighting matrix is equivalent to simple OLS cross-sectional regression or the Fama-MacBeth procedure in the sense that it produces the same estimates of the parameters. An advantage of using the GMM framework is in the estimation of the standard errors for the lambda coefficients. Since GMM minimizes time-series and cross-sectional moments simultaneously the GMM standard errors account for the fact that the betas are estimated and also correct for heteroskedasticity and serial correlation in the data. 
Following most of the literature, we report tests of the null hypothesis that all pricing errors $\hat{\alpha}$ are jointly zero which asymptotically follows the $\chi_{N-L}^{2}$ distribution, where $N$ is the number of test assets and $L$ is the number of parameters in the cross-sectional regression. We note, in this context, that the null of zero pricing errors may not be rejected, not because of small pricing errors, but because of high sampling error in the estimated betas as underlined by Lettau and Ludvigson (2001b). We also report some commonly used informal criteria that help assess the goodness-of-fit of the model: the mean absolute error $M A E=\frac{1}{N}\|\hat{\alpha}\|$, the $R^{2}$, and the adjusted- $R^{2}$. However, these results need to be interpreted with some caution as pointed out by Lewellen, Nagel and Shanken (2009).

\subsubsection{Time-Series Regression Tests}

Lewellen and Nagel (2006) point out that tests of conditional models evaluate these models by relying on cross-sectional regressions and do not emphasize time-series intercept tests that require constraints imposed by theory. We therefore evaluate whether the time series intercept restrictions are satisfied in our scaled consumption-based model by testing whether the estimated intercepts from the time series regressions are, if the model is correctly specified, jointly zero. However, the factors in our models are not traded assets. We create (see Kim (2010) for a recent application) maximally correlated portfolios (MCPs) for each of the multiple factors in the scaled C-CAPM. We do this, following Breeden, Gibbons and Litzenberger (1979), by choosing a set of base traded assets and constructing a portfolio that is maximally correlated with the non-traded model factor. Let the excess returns on each asset $i$ in the set of basis assets be denoted by $R_{i}^{b}$ then the MCP $f_{k}^{*}$ corresponding to factor $f_{k}$ is created using:

$$
f_{k, t+1}^{*}=\widehat{\omega}_{k, 1} R_{1, t+1}^{b}+\widehat{\omega}_{k, 2} R_{2, t+1}^{b} \cdots+\widehat{\omega}_{k, m} R_{m, t+1}^{b}
$$

where the $\widehat{\omega}_{k, 1}$ are the fitted values obtained from the regression:

$$
f_{k, t+1}=\omega_{0,1}+\omega_{k, 1} R_{1, t+1}^{b}+\ldots+\omega_{k, m} R_{m, t+1}^{b}+\eta_{k, t+1}
$$

where $\widehat{\omega}_{k, i}$ are the estimated coefficients for each of the test assets $i \ldots m$.. In other words, these estimated coefficients are used as portfolio weights to construct the MCP - in our case the base assets are the carry trade portfolios and a set of equity market portfolios. We can now apply the Gibbons, Ross, Shanken (1989) or GRS test to our consumption-based model using these MCPs which are traded assets. In this test, the null hypothesis is that the intercept in the time series regression of the test assets on MCPs are jointly zero. In other words we run the following time series regression:

$$
R_{i}^{i e}=\alpha_{i t}^{*}+\beta_{1}^{*} f_{1, t}^{*}+\ldots+\beta_{k}^{*} f_{k, t}^{*}+\epsilon_{k, t}
$$

and test the null hypothesis that: $H_{0}: \alpha_{i t}^{*}=0, \forall i$. Gibbons, Ross and Shanken (1989) provide the finite sample test statistic and its distribution under the null hypothesis, assuming that the residuals are jointly normally distributed. The GRS test statistic is given by:

$$
\frac{(T-N-K))}{N}\left(1+E_{T}\left(f^{*}\right)^{\prime} \widehat{\Omega}^{-1} E_{T}\left(f^{*}\right)^{-1}\right) \widehat{\alpha}^{* \prime} \widehat{\Sigma}^{-1} \widehat{\alpha}^{* \sim} F(N, T-N-K)
$$


where: $\widehat{\alpha}^{*}=\left[\widehat{\alpha}_{1}^{*} \ldots \widehat{\alpha}_{N}^{*}\right]^{\prime}, E_{T}\left(f^{*}\right)=T^{-1} f_{t}^{*}, \widehat{\Omega}=T^{-1} \sum_{t=1}^{T}\left(f_{t}^{*}-E_{T}\left(f^{*}\right)\right)\left(f_{t}^{*}-E_{T}\left(f^{*}\right)^{\prime}\right)$, and $\widehat{\Sigma}=T^{-1} \sum_{t=1}^{T} \widehat{\epsilon}_{t}^{*} \widehat{\epsilon}_{t}^{*^{\prime}}, \widehat{\epsilon}_{t}^{*}=\left(\widehat{\epsilon}_{1, t}^{*}, \ldots, \widehat{\epsilon}_{N, t}^{*}\right)$.

\section{Data}

Recent research has used, as test assets, several different data sets of multi-currency carry trade portfolios. Lustig and Verdelhan (2007) were the first to use annual returns on 8 such tradeable currency portfolios. Their sample, from 1953-2002, consists of equally weighted currency portfolios sorted on the basis of country interest rate differential with the US. Most subsequent work uses higher frequency monthly returns. For example, Lustig, Roussanov and Verdelhan (2011) use monthly returns on six currency portfolios from November 1983 to December 2009. Burnside (2011) and Burnside, Eichenbaum, Kleshchelski and Rebelo (2011) also construct a similar set of test assets over the periods 1976-2010 while Menkhoff, Sarno, Schmeling and Schrimpf (2010) use five carry trade portfolios.

The procedure generally followed, in these papers, to create the carry trade test asset portfolios is as follows. A monthly series of spot and forward prices dollars is obtained using daily spot and forward exchange rates from Reuters/WMR and Barclays that are available on Datastream. Most studies use two sub-samples; a larger sample that includes developed and emerging economies and a smaller sample with data only from a group of developed countries. Next, the available currencies are sorted into portfolios (usually six) according to their forward discount against the US dollar. The first portfolio contains currencies with the smallest forward discounts (the lowest interest rates), and so on - with the last portfolio consisting of those currencies with the largest forward discounts (and therefore the highest interest rates). Next, the log currency excess return is computed for each portfolio by taking the average of the log currency excess returns in each portfolio. In this paper, we use the following data. Our main data consists of quarterly returns of 6 FX carry trade portfolios. These portfolios are the same used at a monthly frequency in Lustig, Roussanov and Verdelhan (2011). We use quarterly returns computed from monthly returns since other macro data are only available at quarterly frequency. In addition, as an out-of-sample check, we also report results using the annual and quarterly returns on the 8 portfolios used in Lustig and Verdelhan $(2007)^{3}$.

\subsection{Consumption and Other Macro Data}

We use data on per capita consumption of nondurables and services and the per capital stock of consumer durables in constant 2005 dollars using data from the BEA (NIPA Table 1, NIPA Table 7, Fixed Assets Table 1 and Fixed Assets Table 9). The NIPA files that we use are: (1) quarterly nominal expenditure on nondurables and services, and durables; (2) quarterly price deflators for nondurables and services; (3) quarterly real purchases of nondurables, services and durables; (3) the annual nominal expenditure series for nondurables, services and durables; (4) the quarterly population series; (5) and the annual price deflator

\footnotetext{
${ }^{3}$ We thank Lustig and Verdelhan (2007) and Lustig, Roussanov and Verdelhan (2011) for generously making this data publicly available.
} 
for nondurables and services. Our transformations follow those outlined in Burnside (2011). The equity market data is from Professor's French web site.

Lustig and Verdelhan (2007) have made available data at quarterly and annual frequency on the carry trade portfolios. They also make available data on non-durable and durable consumption growth, the excess stock market return and the Fama-French factors. We use their data, for the sample period 1953-2002, in order to facilitate comparison with their results. Their data uses NIPA price deflators with the base year 1996 and they also use per household consumption obtained by dividing by the number of households.

\subsection{Empirical Estimation of NXA}

We are interested in calculating $n x a$, a measure of the cyclical component of external imbalances. To construct this series we require quarterly estimates of the US net and gross positions at market value between 1984/01 and 2010/01. The data on gross asset and liability positions of the US is published by the Bureau of Economic Analysis (International Investment position data) and is available on line at the annual frequency. To obtain quarterly estimates, we first recalculate the BEA's gross positions with foreign investment at market value. Then, by combining quarterly data on the cumulative current account and the quarterly gross positions used by Gourinchas and Rey (2007), for the period 1952/01 to 2004/01, we update their gross external assets and liabilities series up to 2010/01.

The ratios of exports, imports, external assets and liabilities to wealth are not stationary i.e. they exhibit a strong upward trend. We therefore follow Gourinchas and Rey (2007) and "purge" the data from the trend component for each ratio and concentrate on the fluctuations of the net asset and net export variables in deviation from these trends. To construct this, we need detrended $(\log )$ exports $\left(\varepsilon_{t}^{x}\right)$, imports $\left(\varepsilon_{t}^{m}\right)$, gross foreign assets $\left(\varepsilon_{t}^{a}\right)$, and liabilities $\left(\varepsilon_{t}^{l}\right)$ relative to wealth. Because $\ln \widehat{Z}_{t}=\ln \left(\widetilde{Z}_{t}\right)+\varepsilon_{t}^{z}$, by estimating the trends $\left(\widetilde{Z}_{t}\right)$, we will be able to compute the detrended components. We follow Gourinchas and Rey (2007) and use a Hodrick-Prescott filter (lambda $=1,600)^{4}$ for this effect. Using quarterly data from 1983/01 to $20010 / 01$, we estimate $n x a_{t}$. Normalizing weights in eq.(15) e.g., $\mu^{z} / \mu^{x}$, leads to $n x a_{t} \equiv\left|\frac{\mu^{a}}{\mu^{x}}\right| \varepsilon_{t}^{a}-\left|\frac{\mu^{l}}{\mu^{x}}\right| \varepsilon_{t}^{l}+\varepsilon_{t}^{x}-\left|\frac{\mu^{m}}{\mu^{x}}\right| \varepsilon_{t}^{m}$, and using our data we obtain $n x a_{t} \equiv 4.70 \varepsilon_{t}^{a}-5.26 \varepsilon_{t}^{l}+$ $\varepsilon_{t}^{x}-1.56 \varepsilon_{t}^{m}$.

\section{$5 \quad$ Empirical Results}

We now turn to our empirical results using two different sets of data. Our main results use quarterly excess returns data, for the period 1984Q1 to 2010Q1. This data is from Lustig, Roussanov and Verdelhan (2011). We also report, as a test of robustness, results using the data from Lustig and Verdelhan (2007) at both annual and quarterly frequencies from the period 1952-2002. We first report results for the cross-sectional regressions based on FamaMacBeth and cross-sectional regressions estimated using GMM. We also report time series

\footnotetext{
${ }^{4}$ We follow the standard advice and set lambda $=1600$ for quarterly data. Ravn and Uhlig (2002) study how the Hodrick-Prescott filter should be adjusted when changing the frequency of observations, their findings also support lambda $=1600$.
} 
regression results based on a GRS test that uses maximally correlated portfolios of the nontraded factors in our model.

\subsubsection{Summary Statistics}

Table 1 Summarizes the basic statistics for quarterly excess returns on the 6 currency portfolios for the period 1983/01 to 2010/01 that are our main test assets Table 1 . These portfolios are constructed by sorting currencies into six groups at time t based on the one-month forward discount (i.e. nominal interest rate differential) at the end of period $t-1$. Portfolio 1 contains currencies with the lowest interest rates, whereas portfolio 6 contains currencies with the highest interest rates. Since exchange rates are expressed in terms of units of domestic currency (U.S. dollar) per unit of foreign currency, the excess returns are interpretable as U.S. dollar returns. Over the full sample period the carry trade delivers both positive and negative excess returns. For example, for portfolios 1 and 2 the carry trade delivers negative excess returns whereas for portfolios 3, 4, 5 and 6 these are positive. The largest spread (between the second and 6 th portfolio) is $1.36 \%$. The Sharpe ratios vary from -0.047 (portfolios 2) to 0.222 (portfolio 6). Notably, however, the carry trade returns exhibit departures from normality, as the reported measures of skewness and kurtosis show.

Descriptive statistics for the factors (nondurables and durable consumption growth, the value weighted US stock market index, the excess market return and the conditioning variables, $n x a$ ) are reported in Tables 2 and 3. Nondurable consumption growth has mean $0.408 \%$ and standard deviation $0.393 \%$ per quarter. Durable consumption growth has mean $1.053 \%$ and standard deviation $0.480 \%$. The correlation between them is 0.443 . Durable consumption growth is much more persistent than nondurable consumption growth. The first-order autocorrelations are 0.924 and 0.512 , respectively. The mean excess returns on the market portfolio, which can be interpreted as the equity premium, is $1.71 \%$ per quarter in this sample. The market returns have a small correlation with the consumption-based factors, especially with durable consumption growth $(-0.075$ with the excess market return and -0.059 with the market return). nxa is negative for this sample period (its mean is -0.004) and shows very low correlation with the other factors.

\subsubsection{Results of Cross-Sectional Regressions}

We report in Table 4 the results of estimating Fama-MacBeth regressions using quarterly data from 1984Q1-2010Q1. We report results for five models. The first three are unconditional versions of the classical CAPM, the C-CAPM and the Yogo (2006) three factor C-CAPM. Models 4 and 5, in this Table, are the conditional version of the classical CAPM and the C-CAPM. These have been the main models relied in the recent literature on carry trade risk and return including Lustig and Verdelhan (2007) and Burnside (2011). We find, in Table 4 that the unconditional models have R-squared ranging from a $83 \%$ for the Yogo model to $68 \%$ for the classical CAPM. However, the standard C-CAPM fares badly with a low R-squared. Its adjusted R-squared is negative suggesting that even a model with a constant does better. Out of the unconditional models, the Yogo model has the lowest Mean Absolute Error (MAE) about $15 \%$ while that of the CAPM is $20 \%$ and that of the C-CAPM is around $44 \%$. In Table 4 , rows 4 and 5 , report the conditional version of the classical CAPM and the scaled factor C-CAPM using $n x a_{t-1}$ as a scaling variable. These results are very interesting. We find that 
the conditional version of the CAPM has an R-squared of $58 \%$ and an adjusted R-squared of $15 \%$. In the case of conditional models the adjusted R-squared may be a relevant statistic as these models have more factors than their unconditional counterparts. As seen in row 5 of Table4 the conditional C-CAPM has an R-squared of $98 \%$ and an adjusted R-squared of $95 \%$. The MAE in the case of the conditional C-CAPM (0.06), is the smallest for our test assets, as compared to all the other candidate models used.

Further, we find that in the unconditional models the market portfolio has a significant market price of risk for the CAPM. However, the market price of risk is only marginally significant for the unconditional C-CAPM consumption growth factor using OLS standard errors. As is well known, the Shanken correction is large non-traded factors and this results in the $\lambda$ for this factor not being significant when using Shanken corrected or GMM t statistics. In the case of the conditional CAPM the price of risk for $n x a$ and the market risk premium are significant when using OLS standard errors. More importantly, in the case of the conditional CAPM we find that the scaled factor $\left(\Delta c_{t} \cdot n x a_{t-1}\right)$ has a significant market price of risk using OLS, Shanken-corrected and CSR-GMM-corrected standard errors.

We also report in Table 5 results of Fama-MacBeth regressions where we impose the constraint that the constant equals zero. Broadly, these results are similar to those in the case where the intercept is freely estimated. Specifically, the conditional C-CAPM (row 5) has an R-squared of $98 \%$ and also has the smallest MAE out of all the models we use. Finally we find that again the scaled factor $\left(\Delta c_{t} \cdot n x a_{t-1}\right)$ is still marginally significant when Shankencorrected and CSR-GMM-corrected standard errors are used.

\subsubsection{Results of Time-Series Regressions}

We report results for the GRS test using our main data set which uses quarterly data in Tables 6 . Since the factors in the models we use are not traded we create, as outlined earlier, maximally correlated portfolios (MCPs) with these factors following Gibbons, Breeden and Litzenberger (1989). These MCPs are then used in the GRS test for the null hypotheses that the intercept term is zero. In other words a high (low) p-value indicates that the model is not rejected (rejected). We use the following sets of test assets to create the MCPs. The first set is the carry trade portfolios augmented by 10 size decile equity market portfolios and the second set consists of the carry trade portfolios and 10 Fama-French book-to-market portfolios.

We find using quarterly data over the period 1984-2010, as indicated in Table 6, that the null hypothesis that the time-series intercepts are jointly zero is rejected for the unconditional C-CAPM at the $5 \%$ level. In contrast for the conditional version of the C-CAPM the null is not rejected. In the cases of the unconditional versions of the classical CAPM, the Fama-French three-factor model and the Yogo models also we cannot reject the null that the intercepts are equal to zero.

\subsubsection{Predictive Ability of NXA}

We now discuss what underlies the empirical results of the tests of conditional CAPM and conditional C-CAPM with $n x a$, a measure of cyclical component of external imbalances, as a state variable. As already pointed by Gourinchas and Rey (2007), nxa reflects underlying fundamentals that determine the exchange rate of US currency with respect to a set of currencies of other countries. It should therefore have predictive power for US dollar exchange 
rate. In order to investigate that, we run a standard regression of the form:

$$
r_{t+1}=\alpha+\beta n x a_{t}+\varepsilon_{t+1}
$$

As an explanatory variable, we use the net change in a trade weighted exchange index. The index is computed as a weighted average of the foreign exchange value of the US dollar against the currencies of a broad group of major US trading partners. The index is available from 1973 in the FRED database. In our predictability exercise we use data over the period 1973Q1-2010Q1

We report in Table 7 estimation results of a predictive regression of $n x a$ for the trade weighted index. We find that, for sample 1973Q1-2010Q1, the nxa indeed has a strong predictive power for the foreign exchange rate of US dollar with respect to other currencies. The coefficient on $n x a$ is significant and the explanatory power of $n x a$ is as high as $6 \%$.

\subsection{Tests for Robustness}

We also perform several tests to assess the robustness of our results. We report in Tables A2.1 and A2.2 the results of estimating Fama-MacBeth regressions using annual data. Here we use the same data set of portfolios as is used in Lustig and Verdelhan (2005). We note here that this data set has 8 carry trade portfolios and span the period 1952-2002. We again report the cross-sectional results, using Fama-MacBeth regressions, for both cases: with and without an intercept term. These results confirm the evidence we find for quarterly returns. The conditional C-CAPM with scaled factors, now using an annual measure of $n x a$, can explain a large part of the variation in conditional consumption betas, based on a variety of criteria. We also report in Table A2.3 the results of a GRS test and find no evidence that our base model, the conditional C-CAPM is mis-specified. Finally, in Table A3.1 we report the predictability results for annual data, using eq.(26), in the spirit of those reported in Table 7. These again confirm the high predictive ability of $n x a$ for the foreign exchange rate of US dollar with respect to other currencies as well on annual frequency.

In ongoing work we have estimated SDF-GMM version of the model, used alternate time series regression-based tests of model fit and estimation methods that allow for time varying betas. These results will be added in the next version of this paper.

\section{Summary and Conclusion}

In this paper we use a conditional version consumption-based asset pricing model with power utility to explain the difference between the average excess returns on carry trade portfolios. In contrast to previous research on exchange rates, which uses scaled returns, our model uses a stochastic discount factor, in the spirit of Lettau and Ludvigson (2005). Our conditioning variable - the net foreign assets for the US - is are computed following Gourinchas and Rey (2007). It has predictive power for multilateral exchange rates and also for carry trade portfolios. We find that this model has is able to explain $97 \%$ of the variation in the crosssection of carry trade risk premia. We also test time series restrictions imposed on the model by theory and find that the model is well specified. Finally we find that the model is able to price annual carry trade portfolio using a longer span of data covering a longer time period. 
In ongoing work, we are exploring additional test of time series restrictions as well as alternate estimation method that allow for time varying conditional betas. We hope to elaborate on these results in the next version of the paper. Overall, our results suggest that standard consumption-based models do still have a role to play in explaining the risk return profile of carry trade portfolios if we allow for stochastic discount factors that allow for state-dependence using appropriate scaling with conditional information. 


\section{References}

Abel, A.B, 1990. Asset Prices under Habit Formation and Catching Up with the Joneses. American Economic Review 80(2), 38-42.

Adrian, T., Rosenberg, J., 2008. Stock Returns and Volatility: Pricing the Short-Run and Long-Run Components of Market Risk. Journal of Finance 63(6), 2997-3030.

Ang, A., Hodrick, B., Xing, Y., Zhang, X., 2006. The Cross-Section of Volatility and Expected Returns. Journal of Finance 61(1), 259-299.

Breeden, D.T., Gibbons, M.R., Litzenberger, R.H. 1989. Empirical Tests of the ConsumptionOriented CAPM. Journal of Finance 44(2), 231-62.

Burnside, C., 2007. The cross-section of foreign currency risk premia and consumption growth risk: A comment. NBER Working paper 13129.

Burnside, C., 2011. The cross-section of foreign currency risk premia and consumption growth risk: A comment. NBER Working paper 13129 forthcoming American Economic Review.

Burnside, C., Eichenbaum, M., Rebelo, S., 2011. Carry Trade and Momentum in Currency Markets. NBER Working Paper 16942 forthcoming Annual Review of Financial Economics.

Burnside, C., Eichenbaum, M., Kleshchelski, I., Rebelo, S., 2011. Do Peso Problems Explain the Returns to the Carry Trade? Review of Financial Studies 24(3), 853-91.

Campbell, J.Y., Cochrane, J.H., 1999. By Force of Habit: A Consumption-Based Explanation of Aggregate Stock Market Behavior. Journal of Political Economy 107(2), 205-251.

Cochrane, J.H. 1996. A Cross-Sectional Test of an Investment-Base Asset Pricing Model. Journal of Political Economy, 104(3), 572-621.

Cochrane, J.H., 2005. Asset Pricing. Princeton University Press, Princeton, NJ.

Engel, C., 1996. The forward discount anomaly and the risk premium: a survey of recent evidence. Journal of Empirical Finance 3, 123-191.

Fama, E.F., MacBeth. J., 1973. Risk, Return, and Equilibrium: Empirical Tests. Journal of Political Economy 81(3), 607-636.

Fama, E.F., French, K.R., 1992. The Cross-Section of Expected Stock Returns. Journal of Finance 47(2), 427-465.

Fama, E.F., French, K.R., 1993. Common Risk Factors in the Returns on Stocks and Bonds. Journal of Financial Economics 33(1), 3-56.

Ferson, W.E., Harvey, C.R., 1999. Conditioning Variables and the Cross-Section of Stock Returns. NBER Working Paper 7009. 
Gibbons, M.R., Ross, S.A., Shanken, J., 1989. A test of the Efficiency of a Given Portfolio. Econometrica 57(5), 1121-1152.

Gourinchas, P., Rey, H., 2007. International Financial Adjustment. Journal of Political Economy $115(4), 665-703$.

Hansen, L.P., Richard, D.F., 1987. The Role of Conditioning Information in Deducing Testable Restrictions Implied by Dynamic Asset Pricing Models. Econometrica 55(3), 587614.

Jagannathan, R., Wang, Z., 1998. An Asymptotic Theory for Estimating Beta-Pricing Models Using Cross-Sectional Regression. Journal of Finance 53(4), 1285-1309.

Jagannathan, R., Wang, Z., 1996. The Conditional CAPM and the Cross-Section of Expected Returns. Journal of Finance 51(1), 3-54.

Kim, J., 2010.Evaluating Time-Series Restrictions for Cross-Sections of Expected Returns: Multifactor CCAPMs. KAIST Business School Working Paper Series No. 2010-006.

Lettau, M., Ludvigson, S.C., 2001a. Consumption,Aggregate Wealth and Expected Stock Returns. Journal of Finance 56(3), 815-849.

Lettau, M., Ludvigson, S.C., 2001b. Resurrecting the (C)CAPM: A Cross-Sectional Test When Risk Premia are Time-Varying. Journal of Political Economy 109(6), 1238-1287.

Lettau, M., Ludvigson, S.C., 2005. Expected Returns and Expected Dividend Growth. Journal of Financial Economics 76(3), 583-626.

Lewellen, J.W., Nagel, S. 2006. The Conditional CAPM Does Not Explain Asset Pricing Anomalies. Journal of Financial Economics 82(2), 289-314.

Lewellen, J., Nagel, S., Shanken, J., 2009. A Skeptical Appraisal of Asset Pricing Tests. Journal of Financial Economics 96(2), 175-194.

Ludvigson, S.C., 2011. Advances in Consumption-Based Asset Pricing: Empirical Tests. Forthcoming in Volume 2 of the Handbook of the Economics of Finance.

Lustig, H., Verdelhan, A., 2007. The cross-section of foreign currency risk premia and consumption growth risk. American Economic Review 97, 89-117.

Lustig, H., Verdelhan, A., 2008. Discussion of Carry Trades and Currency Crashes. NBER Macroeconomics Annual 23(1), 361-384.

Lustig, H., Roussanov, N., Verdelhan, A., 2011. Common Risk Factors in Currency Markets. Forthcoming Review of Financial Studies.

Menkhoff, L., Sarno, L., Schmeling, M., Schrimpf, A., 2011. Carry Trades and Global Foreign Exchange Volatility. Forthcoming Journal of Finance. 
Newey, W.K., West, K.D., 1987. A Simple, Positive Semi-definite, Heteroscedasticity and Autocorrelation Consistent Covariance Matrix. Econometrica 55(3), 703-708.

Nitschka, T., 2007. Consumption growth, uncovered equity parity and the cross-section of returns on foreign currencies. University of Zurich, Institute for Empirical Research in Economics Working Paper.

Ravn, M.O., Uhlig, H., 2002. On adjusting the HP-filter for the frequency of observations. Review of Economics and Statistics 84(2), 371-376.

Shanken, J., 1992. On the Estimation of Beta Pricing Models. Review of Financial Studies $5(1), 1-34$.

Verdelhan, A., 2010. A Habit-Based Explanation of the Exchange Rate Risk Premium. Journal of Finance 65(1), 123-145.

Yogo, M., 2006. A Consumption-Based Explanation of Expected Stock Returns. Journal of Finance 61(2), 539-580. 
Table 1: Summary Statistics for US Investor's Excess Return: 8 currency portfolios

\begin{tabular}{lllllllll}
\hline \multicolumn{2}{l}{ Sample Period: $1953 / 04-2009 / 02$} \\
\hline \hline Portfolio & 1 & 2 & 3 & 4 & 5 & 6 & 7 & 8 \\
\hline mean & -0.221 & -0.265 & 0.309 & 0.426 & 0.321 & 0.658 & 0.698 & 0.744 \\
stdev & 4.640 & 4.445 & 4.714 & 4.382 & 4.408 & 4.530 & 4.359 & 3.955 \\
SR & -0.048 & 0.060 & 0.066 & .097 & 0.073 & 0.145 & 0.160 & 0.188 \\
\hline
\end{tabular}

Notes: Table 1 reports the mean of the real excess returns (in percentage points), the standard deviation (stdev) and the Sharpe ratio (SR) for a US investor. The portfolios are constructed by sorting currencies into eight groups at time $t$ based on the one-month forward discount (i.e nominal interest rate differential) at the end of period $t-1$. Portfolio 1 contains currencies with the lowest interest rates. Portfolio 8 contains currencies with the highest interest rates. The data is quarterly for the period 1953/04-2009/02 and it is an updated version of Lustig and Verdelhan (2007). 
Table 2: Summary Statistics for Pricing Factors: quarterly frequency

\begin{tabular}{lccccc}
\hline \multicolumn{5}{l}{ Sample Period: $1953 / 04-2009 / 02$} \\
\hline \hline Summary Statistics & Mean & St dev & Kurtosis & Skewness & Autocorrelation \\
\hline$\Delta c$ & 0.485 & 0.479 & 4.496 & -0.345 & 0.385 \\
$\Delta d$ & 0.961 & 0.504 & 2.427 & -0.405 & 0.906 \\
$\mathrm{R}_{v w}$ & 2.851 & 8.426 & 3.892 & -0.560 & 0.075 \\
$\mathrm{R}_{v w}-\mathrm{R}_{f}$ & 1.620 & 8.488 & 3.832 & -0.562 & 0.081 \\
$\mathrm{nxa}$ & 0.000 & 0.395 & 5.136 & -0.054 & 0.119 \\
\hline
\end{tabular}

Notes: Table 2 reports summary statistics for the quarterly factors. $\Delta c$ is real per household consumptions (nondurables and services) growth, $\Delta \mathrm{d}$ is real per household durable consumption growth, $\mathrm{R}_{v w}$ is the value weighted US stock market and $\mathrm{R}_{f}$ is the risk-free rate. Sample period is 1953/04:2009/02, except for $n x a, 1953 / 03: 2009 / 01$. The factors are multiplied by 100, except for demeaned $n x a$, by 10 . 
Table 3: Summary Statistics for Pricing Factors: quarterly frequency (2)

\begin{tabular}{|c|c|c|c|c|c|}
\hline \multicolumn{6}{|c|}{ Sample Period: 1953/04-2009/02 } \\
\hline \multicolumn{6}{|l|}{ Correlations } \\
\hline & $\Delta c$ & $\Delta d$ & $\mathrm{R}_{v w}$ & $\mathrm{R}_{v w}-\mathrm{R}_{f}$ & nxa \\
\hline$\Delta c$ & 1 & 0.217 & 0.191 & 0.193 & 0.092 \\
\hline$\Delta d$ & 0.217 & 1 & -0.114 & -0.114 & -0.095 \\
\hline $\mathrm{R}_{v w}$ & 0.191 & -0.114 & 1 & 0.997 & 0.334 \\
\hline $\mathrm{R}_{v w}-\mathrm{R}_{f}$ & 0.193 & -0.114 & 0.997 & 1 & 0.336 \\
\hline nxa & 0.092 & -0.095 & 0.334 & 0.336 & 1 \\
\hline
\end{tabular}

Notes: Table 3 reports the correlations for the quarterly factors. $\Delta c$ is real per household consumptions (nondurables and services) growth, $\Delta \mathrm{d}$ is real per household durable consumption growth, $\mathrm{R}_{v w}$ is the value weighted US stock market and $\mathrm{R}_{f}$ is the risk-free rate. Sample period is 1953/04:2009/02, except for nxa, 1953/03:2009/01. 
Table 4: Cross-Sectional Regressions with Constant: 1953/04-2009/02 (quarterly)

\begin{tabular}{|c|c|c|c|c|c|c|c|c|c|c|c|}
\hline \multirow[b]{2}{*}{ Row } & & \multirow[b]{2}{*}{ Const. } & \multirow[b]{2}{*}{$\widehat{\mathrm{nxa}} t$} & \multicolumn{4}{|c|}{ Factors $t+1$} & \multicolumn{2}{|c|}{ nxat $\cdot$ Factors $t+1$} & \multicolumn{2}{|l|}{$\mathrm{R}^{2}$} \\
\hline & & & & $\left(\mathrm{R}_{v w}-\mathrm{R}_{f}\right)$ & $\Delta c$ & $\Delta d$ & $\mathrm{R}_{v w}$ & $\left(\mathrm{R}_{v w}-\mathrm{R}_{f}\right)$ & $\Delta c$ & $\overline{\mathrm{R}}^{2}$ & MAE \\
\hline \multirow[t]{5}{*}{1} & estimate & 0.316 & & 4.454 & & & & & & 0.210 & 0.204 \\
\hline & iid & 0.140 & & 0.037 & & & & & & 0.078 & \\
\hline & iid-Shanken & 0.167 & & 0.050 & & & & & & & \\
\hline & GMM (6) & 0.210 & & 0.074 & & & & & & & \\
\hline & GMM (auto) & 0.222 & & 0.060 & & & & & & & \\
\hline \multirow[t]{5}{*}{2} & estimate & 0.262 & & & -0.392 & & & & & 0.086 & 0.239 \\
\hline & iid & 0.182 & & & 0.086 & & & & & -0.066 & \\
\hline & iid-Shanken & 0.238 & & & 0.136 & & & & & & \\
\hline & GMM (6) & 0.212 & & & 0.141 & & & & & & \\
\hline & GMM (auto) & 0.241 & & & 0.155 & & & & & & \\
\hline \multirow[t]{5}{*}{3} & estimate & -0.272 & & & -1.201 & -0.320 & 6.199 & & & 0.839 & 0.095 \\
\hline & iid & 0.281 & & & 0.017 & 0.119 & 0.024 & & & 0.719 & \\
\hline & iid-Shanken & 0.421 & & & 0.168 & 0.331 & 0.187 & & & & \\
\hline & GMM (6) & 0.435 & & & 0.174 & 0.326 & 0.201 & & & & \\
\hline & GMM (auto) & 0.436 & & & 0.181 & 0.324 & 0.172 & & & & \\
\hline \multirow[t]{5}{*}{4} & estimate & 0.912 & 0.705 & 2.086 & & & & -4.218 & & 0.884 & 0.079 \\
\hline & iid & 0.018 & 0.018 & 0.177 & & & & 0.066 & & 0.796 & \\
\hline & iid-Shanken & 0.124 & 0.125 & 0.335 & & & & 0.232 & & & \\
\hline & GMM (6) & 0.132 & 0.128 & 0.362 & & & & 0.255 & & & \\
\hline & GMM (auto) & 0.119 & 0.076 & 0.352 & & & & 0.281 & & & \\
\hline \multirow[t]{5}{*}{5} & estimate & 0.278 & 0.582 & & -0.546 & & & & 0.088 & 0.937 & 0.065 \\
\hline & iid & 0.207 & 0.030 & & 0.063 & & & & 0.299 & 0.889 & \\
\hline & iid-Shanken & 0.356 & 0.156 & & 0.221 & & & & 0.407 & & \\
\hline & GMM (6) & 0.365 & 0.144 & & 0.236 & & & & 0.416 & & \\
\hline & GMM (auto) & 0.364 & 0.155 & & 0.252 & & & & 0.422 & & \\
\hline
\end{tabular}

Notes: Table 4 reports the Fama-MacBeth estimates of the risk prices (in percentage points) using 6 rebalanced currency portfolios as test assets. These portfolios are from Lustig, Roussanov and Verdelhan (2011). $\Delta c$ is real per household consumptions (nondurables and services) growth, $\Delta \mathrm{d}$ is real per household durable consumption growth, $\mathrm{R}_{v w}$ is the value weighted US stock market and $R_{f}$ is the risk-free rate. The sample is 1953/04 to 2009/02 (quarterly data). The factors are demeaned. The conditioning variable, $n x a$, has been demeaned and multiplied by 10. We report iid, Shanken corrected, GMM with 6 lags and GMM with auto lag selection p-values. The last two columns report the $\mathrm{R}^{2}$ and adjusted $\bar{R}^{2}$ (centered) and mean absolute pricing error (MAE) (in percentage points). 
Table 5: Cross-Sectional Regressions without Constant: 1953/04-2009/02 (quarterly)

\begin{tabular}{|c|c|c|c|c|c|c|c|c|c|c|}
\hline \multirow[b]{2}{*}{ Row } & & & \multicolumn{4}{|c|}{ Factors $t+1$} & \multicolumn{2}{|c|}{ nxat $_{t} \cdot$ Factors $t+1$} & \multicolumn{2}{|l|}{$\mathrm{R}^{2}$} \\
\hline & & $\widehat{\mathrm{nxa}} t$ & $\left(\mathrm{R}_{v w}-\mathrm{R}_{f}\right)$ & $\Delta c$ & $\Delta d$ & $\mathrm{R}_{v w}$ & $\left(\mathrm{R}_{v w}-\mathrm{R}_{f}\right)$ & $\Delta c$ & $\overline{\mathrm{R}}^{2}$ & MAE \\
\hline \multirow[t]{5}{*}{1} & estimate & & 9.148 & & & & & & -0.620 & 0.322 \\
\hline & iid & & 0.028 & & & & & & -0.851 & \\
\hline & iid-Shanken & & 0.079 & & & & & & & \\
\hline & GMM (6) & & 0.143 & & & & & & & \\
\hline & GMM (auto) & & 0.163 & & & & & & & \\
\hline \multirow[t]{5}{*}{2} & estimate & & & -0.925 & & & & & -0.136 & 0.268 \\
\hline & iid & & & 0.065 & & & & & -0.299 & \\
\hline & iid-Shanken & & & 0.227 & & & & & & \\
\hline & GMM (6) & & & 0.213 & & & & & & \\
\hline & GMM (auto) & & & 0.222 & & & & & & \\
\hline \multirow[t]{5}{*}{3} & estimate & & & -1.111 & -0.473 & 6.645 & & & 0.822 & 0.095 \\
\hline & iid & & & 0.011 & 0.062 & 0.022 & & & 0.716 & \\
\hline & iid-Shanken & & & 0.142 & 0.269 & 0.184 & & & & \\
\hline & GMM (6) & & & 0.134 & 0.291 & 0.213 & & & & \\
\hline & GMM (auto) & & & 0.137 & 0.287 & 0.180 & & & & \\
\hline \multirow[t]{5}{*}{4} & estimate & -0.338 & 4.394 & & & & -7.712 & & 0.315 & 0.170 \\
\hline & iid & 0.171 & 0.037 & & & & 0.015 & & -0.096 & \\
\hline & iid-Shanken & 0.331 & 0.172 & & & & 0.114 & & & \\
\hline & GMM (6) & 0.339 & 0.193 & & & & 0.103 & & & \\
\hline & GMM (auto) & 0.348 & 0.158 & & & & 0.052 & & & \\
\hline \multirow[t]{5}{*}{5} & estimate & 0.385 & & -0.517 & & & & -0.093 & 0.905 & 0.076 \\
\hline & iid & 0.099 & & 0.064 & & & & 0.315 & 0.849 & \\
\hline & iid-Shanken & 0.261 & & 0.218 & & & & 0.411 & & \\
\hline & GMM (6) & 0.246 & & 0.236 & & & & 0.413 & & \\
\hline & GMM (auto) & 0.255 & & 0.248 & & & & 0.417 & & \\
\hline
\end{tabular}

Notes: Table 5 reports the Fama-MacBeth estimates of the risk prices (in percentage points) using 6 rebalanced currency portfolios as test assets. Lustig, Roussanov and Verdelhan (2011). $\Delta c$ is real per household consumptions (nondurables and services) growth, $\Delta \mathrm{d}$ is real per household durable consumption growth, $\mathrm{R}_{v w}$ is the value weighted US stock market and $\mathrm{R}_{f}$ is the risk-free rate. The sample is $1953 / 04$ to $2009 / 02$ (quarterly data). The factors are demeaned. The conditioning variable, $n x a$, has been demeaned and multiplied by 10 . We report iid, Shanken corrected, GMM with 6 lags and GMM with auto lag selection p-values. The last two columns report the $\mathrm{R}^{2}$ and adjusted $\bar{R}^{2}$ (centered) and mean absolute pricing error (MAE) (in percentage points). 
Table 6: GRS Test for 6 currency portfolios

\begin{tabular}{llcc}
\hline Sample Period: $1984 / 01-2010 / 01$ \\
\hline \hline Model & & 6 currency +10 size & 6 currency +10 B/M \\
\hline CAPM & GRS stat & 1.6061 & 1.6034 \\
& p-value & 0.1535 & 0.1543 \\
C-CAPM & GRS stat & 2.4213 & 2.5290 \\
& p-value & 0.0317 & 0.0256 \\
Fama-French three-factor & GRS stat & 1.5447 & 1.8701 \\
& p-value & 0.1719 & 0.0938 \\
Yogo & GRS stat & 0.9919 & 1.4969 \\
& p-value & 0.4353 & 0.1874 \\
conditional CAPM & GRS stat & 1.3125 & 1.6459 \\
& p-value & 0.2590 & 0.1429 \\
conditional C-CAPM & GRS stat & 0.5983 & 0.9379 \\
& p-value & 0.7310 & 0.4717 \\
\hline
\end{tabular}

Notes: Table 6 reports the values of the GRS test statistic (Gibbons, Ross and Shanken, 1989) along with its p-value for different pricing models, specified in the first column. The values of the GRS test come from the time-series regressions of each of the test asset on the multiple correlation portfolio (MCP) which mimics the pricing factor. Specifically, the MCP is the fitted value from the regression of pricing factors on the set of traded portfolios specified in the first row of the column: pricing_factor f $_{t}=\alpha+\theta^{\prime} R_{t}^{e}+\varepsilon_{t}$. For robustness, we use two distinct sets of traded portfolios. The data is sampled at a quarterly frequency and span the period 1984Q1-2010Q1. 
Table 7: In-sample predictive regressions for trade weighted exchange index, 1973Q1-2010Q1

\begin{tabular}{lrrll}
\hline \hline \multicolumn{1}{c}{$\alpha$} & $\hat{\beta}$ & & \\
\hline estimate & 0.836 & 0.772 & $\mathrm{R}^{2}$ & 0.062 \\
se OLS & 0.220 & 0.246 & $\mathrm{R}^{2}$ adj & 0.056 \\
pv OLS & 0.000 & 0.001 & F stat & 9.788 \\
se HAC (0) & 0.219 & 0.212 & $\mathrm{p}$-value & 0.002 \\
pv HAC (0) & 0.000 & 0.000 & MAE & 2.103 \\
se HAC (auto) & 0.244 & 0.216 & $\mathrm{RMSE}$ & 2.668 \\
pv HAC (auto) & 0.000 & 0.000 & $\mathrm{MSE}$ & 7.121 \\
\hline & & & & \\
auto lag selection & 2.000 & & & \\
\hline
\end{tabular}

Notes: Table 7 presents the in-sample prediction results for the return on trade weighted exchange index that represents a weighted average of the foreign exchange value of the US dollar against the currencies of a broad group of major US trading partners. The prediction regression is the following: $r_{t+1}=\alpha+\beta n x a_{t}+\varepsilon_{t+1}$. We report the coefficient estimates of $\alpha$ and $\beta$ as well three types of standard errors: OLS, heteroscedastic and autocorrelation (HAC) errors of Newey and West (1987) with 0 lags and with automatic lag selection, as well as the appropriate p-values. Additionally we report other standard statistics like R-squared, adjusted R-squared, F statistic for the test of joint significance along with its p-value, Mean Average Error (MAE), Root Mean Square Error (RMSE) and Mean Square Error (MSE). The data is sampled at a quarterly frequency and span the period 1973Q1-2010Q1. 


\section{Appendix (Not for Publication)}

This Appendix contains additional results and details of the data that are referred to in the main paper but not included to save space.

Appendix 1 includes the summary statistics for the annual data.

Appendix 2 contains cross-sectional results for annual data.

Appendix 3 reports the predictability results for annual data. 


\section{Appendix 1: Summary Statistics for Annual Data}

Table A1.1: Summary Statistics for US Investor's Excess Return: 8 currency portfolios

\begin{tabular}{lllllllll}
\hline \multicolumn{2}{l}{ Sample Period: $1953-2002$} \\
\hline \hline Portfolio & 1 & 2 & 3 & 4 & 5 & 6 & 7 & 8 \\
\hline mean & -2.283 & -1.373 & -0.457 & -0.535 & -0.306 & 0.675 & 1.649 & 1.244 \\
SR & -0.361 & -0.214 & -0.064 & -0.063 & -0.035 & 0.110 & 0.143 & 0.109 \\
Skewness & .024 & -1.193 & -0.779 & 0.028 & -0.305 & -0.448 & -0.885 & 1.248 \\
Kurtosis & 3.845 & 7.243 & 5.949 & 3.249 & 3.888 & 5.047 & 7.261 & 9.698 \\
\hline
\end{tabular}

Notes: Table A1.1 reports the mean of the real excess returns (in percentage points) and the Sharpe ratio for a US investor. The portfolios are constructed by sorting currencies into eight groups at time $\mathrm{t}$ based on the nominal interest rate differential at the end of period $\mathrm{t}-1$. Portfolio 1 contains currencies with the lowest interest rates. Portfolio 8 contains currencies with the highest interest rates. Portfolios include defaulting countries that have defaulted in previous years. The data is from Lustig and Verdelhan (2007). 
Table A1.2: Summary Statistics for Pricing Factors: annual frequency

\begin{tabular}{lccccc}
\hline \multicolumn{5}{l}{ Sample Period: $1953-2002$} & \\
\hline \hline Summary Statistics & Mean & St dev & Kurtosis & Skewness & Autocorrelation \\
\hline$\Delta c$ & 3.364 & 2.065 & 2.635 & -0.499 & 0.500 \\
$\Delta d$ & 1.557 & 1.466 & 6.441 & -1.425 & 0.292 \\
$\mathrm{R}_{v w}$ & 6.956 & 17.756 & 3.312 & -0.696 & 0.010 \\
$\mathrm{R}_{v w}-R_{f}$ & 6.975 & 18.264 & 2.616 & -0.130 & -0.540 \\
$\mathrm{nxa}$ & -0.010 & 0.483 & 2.835 & 0.187 & 0.152 \\
\hline
\end{tabular}

Notes: Table A1.2 reports summary statistics for the annual factors. $\Delta c$ is real per household consumptions (nondurables and services) growth, $\Delta \mathrm{d}$ is real per household durable consumption growth, $\mathrm{R}_{v w}$ is the value weighted US stock market and $\mathrm{R}_{f}$ is the risk-free rate. Sample period is 1953:2002, except for $n x a, 1952: 2001$. The factors are multiplied by 100, except for nxa, by 10 . 
Table A1.3: Summary Statistics for Pricing Factors: annual frequency (2)

\begin{tabular}{llllll}
\hline Sample Period: & $1953-2002$ & & & \\
\hline \hline Correlations & & & & & \\
& $\Delta c$ & $\Delta d$ & $\mathrm{R}_{v w}$ & $\mathrm{R}_{v w^{-}} \mathrm{R}_{f}$ & $\mathrm{nxa}$ \\
\cline { 2 - 6 }$\Delta c$ & 1 & 0.641 & -0.207 & -0.253 & -0.126 \\
$\Delta d$ & 0.641 & 1 & 0.147 & 0.078 & -0.006 \\
$\mathrm{R}_{v w}$ & -0.207 & 0.147 & 1 & 0.985 & 0.039 \\
$\mathrm{R}_{v w}-\mathrm{R}_{f}$ & -0.253 & 0.078 & 0.985 & 1 & 0.030 \\
$\mathrm{nxa}$ & -0.126 & -0.006 & 0.039 & 0.030 & 1 \\
\hline
\end{tabular}

Notes: Table A1.3 reports the correlations for the annual factors. $\Delta c$ is real per household consumptions (nondurables and services) growth, $\Delta \mathrm{d}$ is real per household durable consumption growth, $\mathrm{R}_{v w}$ is the value weighted US stock market and $\mathrm{R}_{f}$ is the risk-free rate. Sample period is 1953-2002, except for $n x a, 1952-2001$. 


\section{Appendix 2: Estimation Results for Annual Data}

Table A2.1: Cross-Sectional Regressions with Constant: 1953-2002 (annual)

\begin{tabular}{|c|c|c|c|c|c|c|c|c|c|c|c|}
\hline \multirow[b]{2}{*}{ Row } & & \multirow[b]{2}{*}{ Const. } & \multirow[b]{2}{*}{$\widehat{\mathrm{nxa}} t$} & \multicolumn{4}{|c|}{ Factors $t+1$} & \multicolumn{2}{|c|}{$\overline{\text { nxa }_{t} \cdot \text { Factors }} t+1$} & \multicolumn{2}{|l|}{$\overline{\mathrm{R}^{2}}$} \\
\hline & & & & $\left(\mathrm{R}_{v w}-\mathrm{R}_{f}\right)$ & $\Delta c$ & $\Delta d$ & $\mathrm{R}_{v w}$ & $\left(\mathrm{R}_{v w}-\mathrm{R}_{f}\right)$ & $\Delta c$ & $\overline{\mathrm{R}}^{2}$ & MAE \\
\hline \multirow[t]{5}{*}{1} & estimate & 0.019 & & 11.599 & & & & & & 0.165 & 0.951 \\
\hline & iid & 0.492 & & 0.112 & & & & & & 0.026 & \\
\hline & iid-Shanken & 0.493 & & 0.141 & & & & & & & \\
\hline & GMM (6) & 0.494 & & 0.105 & & & & & & & \\
\hline & GMM (auto) & 0.494 & & 0.119 & & & & & & & \\
\hline \multirow[t]{5}{*}{2} & estimate & -3.533 & & & 5.001 & & & & & 0.954 & 0.213 \\
\hline & iid & 0.008 & & & 0.010 & & & & & 0.947 & \\
\hline & iid-Shanken & 0.102 & & & 0.109 & & & & & & \\
\hline & GMM (6) & 0.051 & & & 0.053 & & & & & & \\
\hline & GMM (auto) & 0.051 & & & 0.053 & & & & & & \\
\hline \multirow[t]{5}{*}{3} & estimate & -3.599 & & & 5.102 & 2.337 & -9.548 & & & 0.955 & 0.212 \\
\hline & iid & 0.015 & & & 0.022 & 0.079 & 0.152 & & & 0.921 & \\
\hline & iid-Shanken & 0.119 & & & 0.149 & 0.269 & 0.333 & & & & \\
\hline & GMM (6) & 0.090 & & & 0.130 & 0.223 & 0.316 & & & & \\
\hline & GMM (auto) & 0.090 & & & 0.162 & 0.236 & 0.324 & & & & \\
\hline \multirow[t]{5}{*}{4} & estimate & 1.438 & -0.518 & 2.270 & & & & -8.279 & & 0.905 & 0.297 \\
\hline & iid & 0.094 & 0.024 & 0.407 & & & & 0.089 & & 0.834 & \\
\hline & iid-Shanken & 0.171 & 0.050 & 0.436 & & & & 0.159 & & & \\
\hline & GMM (6) & 0.145 & 0.061 & 0.425 & & & & 0.136 & & & \\
\hline & GMM (auto) & 0.132 & 0.084 & 0.428 & & & & 0.140 & & & \\
\hline \multirow[t]{5}{*}{5} & estimate & -3.052 & -0.296 & & 3.582 & & & & -0.307 & 0.972 & 0.176 \\
\hline & iid & 0.042 & 0.217 & & 0.132 & & & & 0.370 & 0.951 & \\
\hline & iid-Shanken & 0.154 & 0.345 & & 0.278 & & & & 0.434 & & \\
\hline & GMM (6) & 0.119 & 0.281 & & 0.196 & & & & 0.374 & & \\
\hline & GMM (auto) & 0.119 & 0.281 & & 0.196 & & & & 0.374 & & \\
\hline
\end{tabular}

Notes: Table A2.1 reports the Fama-MacBeth estimates of the risk prices (in percentage points) using eight annually rebalanced currency portfolios as test assets. These portfolios are from Lustig and Verdelhan (2007) and include countries that have defaulted. $\Delta c$ is real per household consumptions (nondurables and services) growth, $\Delta \mathrm{d}$ is real per household durable consumption growth, $\mathrm{R}_{v w}$ is the value weighted US stock market and $\mathrm{R}_{f}$ is the risk-free rate. The sample is 1953 to 2002 (annual data). The factors are demeaned. The conditioning variable, $n x a$, has been demeaned and multiplied by 10 . The iid p-values are reported between (), Shanken corrected p-values inside [], GMM p-values with 6 lags inside \{\} and GMM values with auto lag selection between $<>$. The last two columns report the $\mathrm{R}^{2}$ and adjusted $\bar{R}^{2}$ (centered) and mean absolute pricing error (MAE) (in percentage points). 
Table A2.2: Cross-Sectional Regressions without Constant: 1953-2002 (annual)

\begin{tabular}{|c|c|c|c|c|c|c|c|c|c|c|}
\hline \multirow[b]{2}{*}{ Row } & & \multirow[b]{2}{*}{$\widehat{\mathrm{nxa}} t$} & \multicolumn{4}{|c|}{ Factors $t+1$} & \multicolumn{2}{|c|}{$\mathrm{nxa}_{t} \cdot$ Factors $t+1$} & \multicolumn{2}{|l|}{$\overline{\mathrm{R}^{2}}$} \\
\hline & & & $\left(\mathrm{R}_{v w}-\mathrm{R}_{f}\right)$ & $\Delta c$ & $\Delta d$ & $\mathrm{R}_{v w}$ & $\left(\mathrm{R}_{v w}-\mathrm{R}_{f}\right)$ & $\Delta c$ & $\overline{\mathrm{R}}^{2}$ & MAE \\
\hline \multirow[t]{5}{*}{1} & estimate & & 11.455 & & & & & & 0.165 & 0.951 \\
\hline & iid & & 0.156 & & & & & & 0.046 & \\
\hline & iid-Shanken & & 0.189 & & & & & & & \\
\hline & GMM (6) & & 0.204 & & & & & & & \\
\hline & GMM (auto) & & 0.221 & & & & & & & \\
\hline \multirow[t]{5}{*}{2} & estimate & & & 0.341 & & & & & 0.019 & 1.056 \\
\hline & iid & & & 0.393 & & & & & -0.121 & \\
\hline & iid-Shanken & & & 0.394 & & & & & & \\
\hline & GMM (6) & & & 0.391 & & & & & & \\
\hline & GMM (auto) & & & 0.391 & & & & & & \\
\hline \multirow[t]{5}{*}{3} & estimate & & & -0.156 & -0.642 & 8.733 & & & 0.404 & 0.864 \\
\hline & iid & & & 0.449 & 0.265 & 0.189 & & & 0.046 & \\
\hline & iid-Shanken & & & 0.461 & 0.316 & 0.247 & & & & \\
\hline & GMM (6) & & & 0.455 & 0.294 & 0.254 & & & & \\
\hline & GMM (auto) & & & 0.460 & 0.288 & 0.260 & & & & \\
\hline \multirow[t]{5}{*}{4} & estimate & -0.469 & -3.007 & & & & -13.986 & & 0.773 & 0.490 \\
\hline & iid & 0.026 & 0.370 & & & & 0.013 & & 0.637 & \\
\hline & iid-Shanken & 0.080 & 0.422 & & & & 0.047 & & & \\
\hline & GMM (6) & 0.076 & 0.415 & & & & 0.056 & & & \\
\hline & GMM (auto) & 0.103 & 0.406 & & & & 0.063 & & & \\
\hline \multirow[t]{5}{*}{5} & estimate & -0.710 & & -2.987 & & & & -1.643 & 0.620 & 0.607 \\
\hline & iid & 0.025 & & 0.056 & & & & 0.032 & 0.392 & \\
\hline & iid-Shanken & 0.154 & & 0.226 & & & & 0.168 & & \\
\hline & GMM (6) & 0.129 & & 0.186 & & & & 0.171 & & \\
\hline & GMM (auto) & 0.129 & & 0.186 & & & & 0.171 & & \\
\hline
\end{tabular}

Notes: Table A2.2 reports the Fama-MacBeth estimates of the risk prices (in percentage points) using eight annually rebalanced currency portfolios as test assets. These portfolios are from Lustig and Verdelhan (2007) and include countries that have defaulted. $\Delta c$ is real per household consumptions (nondurables and services) growth, $\Delta \mathrm{d}$ is real per household durable consumption growth, $\mathrm{R}_{v w}$ is the value weighted US stock market and $\mathrm{R}_{f}$ is the risk-free rate. The sample is 1953 to 2002 (annual data). The factors are demeaned. The conditioning variable, $n x a$, has been demeaned and multiplied by 10 . The iid $\mathrm{p}$-values are reported between (), Shanken corrected p-values inside [], GMM p-values with 6 lags inside \{\} and GMM values with auto lag selection between $<>$. The last two columns report the $\mathrm{R}^{2}$ and adjusted $\bar{R}^{2}$ (centered) and mean absolute pricing error (MAE) (in percentage points). 
Table A2.3: GRS Test for 8 currency portfolios

\begin{tabular}{llcc}
\hline Sample Period: 1953-2002 & \multicolumn{3}{c}{} \\
\hline \hline Model & & 6 currency +10 size & 6 currency +10 B/M \\
\hline CAPM & GRS stat & 1.5283 & 1.5450 \\
& p-value & 0.1774 & 0.1719 \\
C-CAPM & GRS stat & 2.9288 & 2.7024 \\
& p-value & 0.0111 & 0.0174 \\
Fama-French three-factor & GRS stat & 1.6555 & 1.3398 \\
& p-value & 0.1408 & 0.2534 \\
Yogo & GRS stat & 1.4463 & 1.8710 \\
& p-value & 0.2086 & 0.0929 \\
conditional CAPM & GRS stat & 0.5320 & 1.0193 \\
& p-value & 0.8521 & 0.4380 \\
conditional C-CAPM & GRS stat & 0.8675 & 1.8300 \\
& p-value & 0.5516 & 0.1006 \\
\hline
\end{tabular}

Notes: Table A2.3 reports the values of the GRS test statistic (Gibbons, Ross and Shanken, 1989) along with its p-value for different pricing models, specified in the first column. The values of the GRS test come from the time-series regressions of each of the test asset on the multiple correlation portfolio (MCP) which mimics the pricing factor. Specifically, the MCP is the fitted value from the regression of pricing factors on the set of traded portfolios specified in the first row of the column: pricing_factor ${ }_{t}=\alpha+\theta^{\prime} R_{t}^{e}+\varepsilon_{t}$. For robustness, we use two distinct sets of traded portfolios. The data is sampled at an annual frequency and span the period 1953-2002. 


\section{Appendix 3: Predictability Results for Annual Data}

Table A3.1: In-sample predictive regressions for trade weighted exchange index, 1973-2010

\begin{tabular}{lrrlr}
\hline \hline & $\alpha$ & $\hat{\beta}$ & & \\
\hline estimate & 3.438 & 5.559 & $\mathrm{R}^{2}$ & 0.246 \\
se OLS & 0.989 & 1.645 & $\mathrm{R}^{2}$ adj & 0.224 \\
pv OLS & 0.000 & 0.000 & F stat & 11.421 \\
se HAC (0) & 0.965 & 1.666 & p-value & 0.001 \\
pv HAC (0) & 0.000 & 0.001 & MAE & 4.952 \\
se HAC (auto) & 1.105 & 1.844 & RMSE & 5.852 \\
pv HAC (auto) & 0.001 & 0.002 & MSE & 34.246 \\
\hline & & & & \\
auto lag selection & 2.000 & & & \\
\hline
\end{tabular}

Notes: Table A3.1 presents the in-sample prediction results for the return on trade weighted exchange index that represents a weighted average of the foreign exchange value of the US dollar against the currencies of a broad group of major US trading partners. The prediction regression is the following: $r_{t+1}=\alpha+\beta n x a_{t}+\varepsilon_{t+1}$. We report the coefficient estimates of $\alpha$ and $\beta$ as well three types of standard errors: OLS, heteroscedastic and autocorrelation (HAC) errors of Newey and West (1987) with 0 lags and with automatic lag selection, as well as the appropriate p-values. Additionally we report other standard statistics like R-squared, adjusted R-squared, F statistic for the test of joint significance along with its p-value, Mean Average Error (MAE), Root Mean Square Error (RMSE) and Mean Square Error (MSE). The data is sampled at an annual frequency and span the period 1973-2010. 